\section{Studying diversity}

\section{Luca Cavalli-Sforza}

\author{
Race to the Finish: Identity and \\ G overnance in an Age of $\mathbf{G}$ enomics \\ by Jenny Reardon \\ Princeton University Press, Princeton, \\ NJ, USA \\ $312 \mathrm{pp}, \mathbf{\$ 1 8 / £ 1 2}$ \\ ISBN 0691118574
}

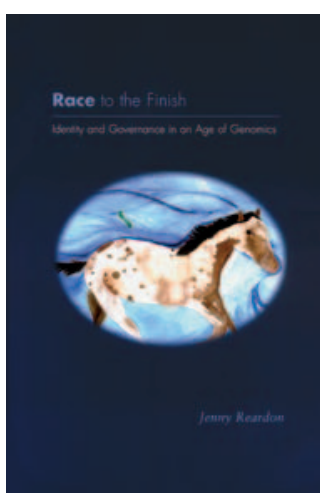

Jenny Reardon's book, Race to the Finish: Identity and Governance in an Age of $\mathrm{G}$ e nom ics, describes the history of the Human Genome Diversity Project (HGDP) and the controversy surrounding it. The HGDP-a suggestion of mine that was made possible by the joint efforts of many friends and colleagues - is not a "failed scientific endeavor", as Steven Epstein claims on the book's back cover, but is alive and kicking. $\mathrm{H}$ is error is probably due to a misleading article published in $\mathrm{N}$ ature in November 2003, which proclaimed the death of the project. My letter correcting this error was not published until 1 April 2004. The beginning of the project, now called HGDP-CEPH (Centre d'Etude du Polymorphisme Humain), was announced in a letter in Science (Cann et al (2002) Science 296: 261). It was soon followed by the first article based on the HGDP-CEPH collection of DNA (Rosenberg et al (2002) Science 298: 2381-2385), which was chosen as the best "biomedical paper of the year" by The Lancet. Thus far, 69 research laboratories have received the HGDP-CEPH DNA collection, which comprises 1,064 individuals from 52 populations on five continents, and more laboratories are waiting to receive the D NA collection, which again shows that the HGDP-CEPH is anything but 'dead'. I summarized the project in a recent article (Cavalli-Sforza LL (2005) N at Rev Genet 6: 333-340)

Reardon performs a careful and intensive analysis of the controversies that delayed the project and makes suggestions to solve the conflict between politics and science. Although I like the book, I think Reardon underestimates the maliciousness of and the damage caused by the attack against the HGDP-CEPH by the Rural Advancement Foundation International (RAFI), a private Canadian foundation that continues to be hostile to many similar endeavours. RAFI accused us of many offenses, all false, against their vast network of indigenous American and O ceanic groups. I am convinced that despite RAFI's excellent work in establishing contacts with indigenous groups, their financial support was lagging and they were not really interested in our guilt or innocence. They must have realized that they could use us to build new support for their institution.

RAFI clearly had a strong political interest in being dishonest with us. Science can only proceed in complete honesty, but in politics lying and cheating are part of the game. My collaborators and I are scientists and chose to keep acting as such. Conversely, our total ignorance of the existence of RAFI and their machinations was certainly an error that caused considerable damage. Fortunately, we have good friends among the indigenous groups, and we have no ambition to test all existing populations-we may have lost some because of RAFI's actions but those willing to cooperate with us are more than enough, and are likely to increase in number.

I believe RAFI also had an important part in assuring the failure of meetings that were held in Montreal, Canada, and California and Montana, USA, to discuss the HGDP-CEPH with American Indians. The description of these meetings in chapter six is the weakest part of the book. It could not have been a coincidence that a meeting of strongly motivated opponents of the project was convened in Montreal in September 1996, a few days before and a couple of blocks away from ours. On the first day of our meeting, an important member of the Canadian government was expected to take part. W hen some participants of our opponents' meeting threatened to disrupt our seminar, the Montreal police and the Royal Canadian Mounted Police intervened, and the meeting was delayed. The organizer of the seminar thought it necessary for my safety to have an armed bodyguard follow my every step for the duration of the meeting.
The seminar in Palo Alto (CA, USA) in January 1998 was supposed to be a meeting of HGDP-CEPH organizers with a group of American Indians, convened on our request by Frank Dukepoo, one of very few American Indian geneticists. U nfortunately, Reardon was probably not aware that two of the most important attendees, Debra Harry and Judy Gobert from the Indigenous Peoples Council on Biocolonialism, disrupted the meeting by making strong accusations, preventing balanced discussions with other attendees. Eventually, the two declared they were ashamed they had come and did not want it known that they had attended, and subsequently left. After this, Gobert's later invitation to discuss the HGDP-CEPH in Montana, at a meeting called "Colonialism through Biopiracy" (the title of which the organizers refused to change) could only be interpreted as a cruel joke, or perhaps what the organizers hoped would be the final blow to the project.

I have always felt very sympathetic to the plight of the American Indians, with which I believe I am reasonably familiar, but it is difficult to make progress with people who see you only as a person who shares the same skin colour as those who usurped their ancestors' territories.

Reardon is correct that the present crisis in anthropology has made things more difficult for the HGDP-CEPH, but it is much more destructive for anthropologists and their science. Many people have difficulty in distinguishing between science and technology, ideology and reason, and between different forms of power. It is clear that Reardon is honestly struggling to solve these problems for herself. In her conclusion, she writes that "we might better understand... [the HGDP-CEPH] not as an anomaly or as a failure that we can prevent from repeating itself, but rather as a project struggling to do the difficult work that will be required by any effort to study human genetic differences. To the extent that this admittedly painful process leads to a more reflective understanding of the complexities of race, identity, and human diversity, it might even be thought of as a success."

\section{Luca Cavalli-Sforza is Professor of Genetics, Emeritus(active) in the D epartment of Geneticsat Stanford University, California, USA.}

E-mail: cavalli@stanford.edu

doi:10.1038/sj.embor.7400496 